\section{AIP Mutation in Pituitary Adenomas in the 18th Century and Today}

\author{
Harvinder S. Chahal, M.B., B.S., Karen Stals, B.Sc., Martina Unterländer, Dipl.Biol., \\ David J. Balding, D.Phil., Mark G. Thomas, Ph.D., Ajith V. Kumar, M.D., \\ G. Michael Besser, M.D., A. Brew Atkinson, M.D., Patrick J. Morrison, M.D., \\ Trevor A. Howlett, M.D., Miles J. Levy, M.D., Steve M. Orme, M.D., \\ Scott A. Akker, M.B., B.S., Ph.D., Richard L. Abel, Ph.D., Ashley B. Grossman, M.D., \\ Joachim Burger, Ph.D., Sian Ellard, Ph.D., and Márta Korbonits, M.D., Ph.D.
}

\section{SUMMARY}

Gigantism results when a growth hormone-secreting pituitary adenoma is present before epiphyseal fusion. In 1909, when Harvey Cushing examined the skeleton of an Irish patient who lived from 1761 to $1783,{ }^{1-3}$ he noted an enlarged pituitary fossa. We extracted DNA from the patient's teeth and identified a germline mutation in the aryl hydrocarbon-interacting protein gene (AIP). Four contemporary Northern Irish families who presented with gigantism, acromegaly, or prolactinoma have the same mutation and haplotype associated with the mutated gene. Using coalescent theory, we infer that these persons share a common ancestor who lived about 57 to 66 generations earlier.

P ITUITARY ADENOMAS ARE USUALLY BENIGN, SLOW-GROWING TUMORS that cause symptoms due to excess hormone release, local space-occupying effects, or both. Adenomas that secrete excess growth hormone cause acromegaly. Patients with acromegaly have numerous symptoms and signs, such as hyperhidrosis, prognathism, frontal skull bossing, thickened skin, diabetes mellitus, hypertension, sleep apnea, osteoarthritis, and headache, as well as enlargement of the hands, feet, heart, and other internal organs. Large adenomas expand the pituitary fossa and can lead to visual-field defects and interfere with the production of other pituitary hormones, such as gonadotropic hormones, thyroid-stimulating hormone, or adrenocorticotropin. ${ }^{4}$ Increased prolactin levels are often noted in such patients owing to cosecretion of growth hormone and prolactin (since somatotrophs and lactotrophs have a common developmental origin), pressure on the pituitary stalk, or both.

Untreated acromegaly leads to increased mortality as a result of cardiovascular, cerebrovascular, and pulmonary dysfunction and is associated with a $30 \%$ decrease in life expectancy. ${ }^{4}$ Acromegalic gigantism is most often caused by a pituitary adenoma that secretes excess growth hormone, with the onset of the disorder before epiphyseal fusion. ${ }^{5}$ Although extreme stature characterized these patients in the past, a timely diagnosis and the combination of surgery, medical therapy, and radiation therapy can now usually control the output or the effect of growth hormone and avert a marked increase in height. It has recently been recognized that in acromegaly of childhood onset, patients occasionally have a family history
From the Department of Endocrinology, Barts and the London School of Medicine, Queen Mary University of London (H.S.C., G.M.B., S.A.A., A.B.G., M.K.); the Institute of Genetics (D.J.B.) and the Research Department of Genetics, Evolution and Environment (M.G.T.), University College London; North East Thames Regional Genetics Service, Great Ormond Street Hospital (A.V.K.); and the Department of Mineralogy, Natural History Museum (R.L.A.) - all in London; the Department of Molecular Genetics, Royal Devon and Exeter Foundation Trust (K.S., S.E.), and Peninsula Medical School, University of Exeter (S.E.) - both in Exeter; Regional Centre for Endocrinology and Diabetes, Royal Victoria Hospital (A.B.A.), and the Department of Medical Genetics, Belfast HSC Trust (P.J.M.) - both in Belfast, Northern Ireland; the School of Biomedical Science, University of Ulster, Coleraine, Northern Ireland (P.J.M.); the Department of Endocrinology, University Hospitals of Leicester, Leicester (T.A.H., M.J.L.); and the Department of Endocrinology, St James's University Hospital, Leeds (S.M.O.) - all in the United Kingdom; the Institute of Anthropology, Johannes Gutenberg University, Mainz, Germany (M.U., J.B.); the Department of Evolutionary Biology, Evolutionary Biology Center, Uppsala University, Uppsala, Sweden (M.G.T.). Address reprint requests to Dr. Korbonits at the Department of Endocrinology, Barts and the London School of Medicine, Queen Mary University of London, Charterhouse Sq., London EClA 6BQ, United Kingdom, or at m.korbonits@ qmul.ac.uk.

N Engl J Med 2011;364:43-50. Copyright @ 2011 Massachusetts Medical Society. 


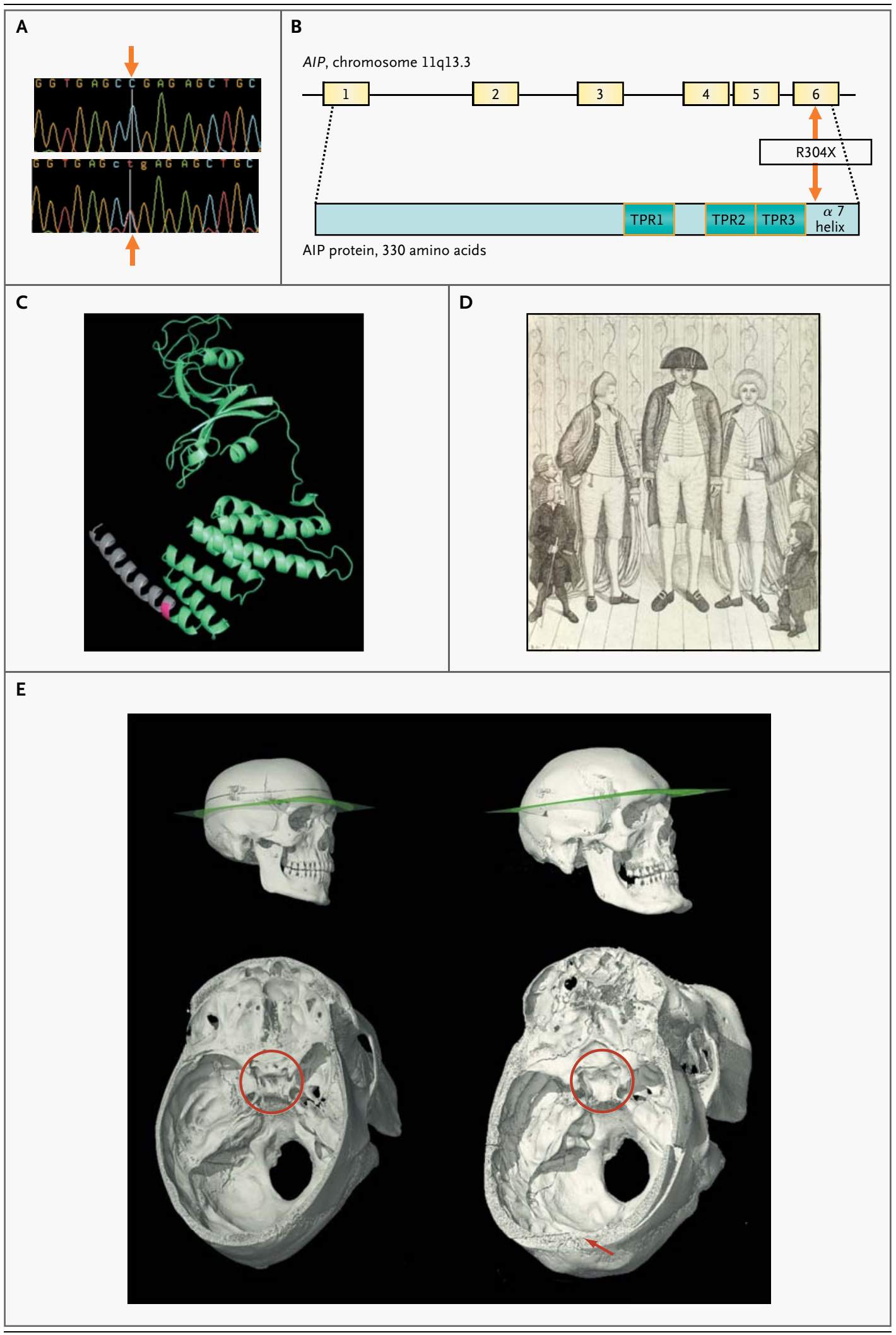

The New England Journal of Medicine 
Figure 1 (facing page). Images of the Index Patient and the Structure and Specific Mutation of AIP.

In Panel A, the aryl hydrocarbon-interacting protein (AIP) sequence change c.910 $\rightarrow T$ (red arrows) generates a premature stop codon, resulting in a truncated protein with loss of the final 26 amino acids. The site appears to be a mutational hot spot, since it is located at a typical CpG site ${ }^{16}$ and has been identified in five families from three countries (three from Italy, ${ }^{6,16}$ one from England, ${ }^{10}$ and one from Romania ${ }^{10}$ ), as well as in two patients with apparently sporadic cases in France and India, in addition to the Irish cases we describe here. It was not found to be present in any other patients with sporadic or familial pituitary adenoma, in patients studied for AIP abnormalities who had other diseases, or in the general population ${ }^{15}$ (and unpublished data). Panel B shows schematic representations of AIP and the AIP protein. The red arrows point to the location of AIP and protein mutations. The AIP protein has three pairs of conserved antiparallel $\alpha$ helixes (tetratricopeptide repeat domains [TPR]) and a final extended $\alpha$ helix, $\alpha 7$. These helical structures are important for the protein-protein binding and antiproliferative action of AIP. ${ }^{10,17}$ Panel C shows a three-dimensional model of AIP based on the crystal structure of the structurally related protein FKBP51. ${ }^{13}$ The red amino acid is num. ber 304 , which is replaced by a termination codon in the families described in this study. This mutation results in a loss of 26 amino acids at the end of the $\alpha 7$ helix (gray). Panel D shows the index patient beside the twin brothers who also had gigantism, in an etching by John Kay (1742-1826) (National Portrait Gallery, London). Panel E shows microtomographic reconstructions of the skull of the index patient (right) alongside a normal male skull (left). The images have been clipped at the plane indicated to allow observation of the differences in the size of the pituitary fossa (red circles), the size of the frontal sinuses, and the thickness of the parietal bone (red arrow).

of acromegaly or prolactinoma; some of these families have a mutation in the gene encoding the aryl hydrocarbon-interacting protein (AIP), which predisposes them to pituitary adenoma formation. ${ }^{6-13}$ In addition, some patients with childhood-onset pituitary adenoma and no apparent family history have been shown to have germline AIP mutations. ${ }^{14,15}$ In our cohort of 140 families with familial isolated pituitary adenoma, ${ }^{10,13}$ we identified four families from Northern Ireland with the same AIP mutation (c.910C $\rightarrow$ T, p.R304X) (Fig. 1A, 1B, and 1C), which is known to be a mutational hot spot. $6,7,10,18$ Functional cell-proliferation and protein-protein binding assays have shown that this mutation results in a truncated, dysfunctional protein. ${ }^{10}$ In view of the geographic clustering of the $\mathrm{c} .910 \mathrm{C} \rightarrow \mathrm{T}$ mutation, we explored the possibility that an 18th-century giant from Northern Ireland (the index patient), whose skeleton is preserved, and the four Northern Irish families we identified inherited the same mutation from a common ancestor.

\section{PAT IENTS}

The index patient was born in Northern Ireland in 1761. As a child he grew rapidly, and in his late teens he was featured in street shows in Ireland. At the age of 19 years, he traveled to London to exhibit himself in similar settings. A contemporary etching shows him in the company of twin brothers, also giants, who were born in a neighboring village (12 km away) and who were said to be related to him $^{3}$ (Fig. 1D). His general health slowly deteriorated, and he died at 22 years of age. Subsequently his skeleton ( $231 \mathrm{~cm}$ [approximately $7 \mathrm{ft}, 7 \mathrm{in}$.] in height) was acquired by the surgeon John Hunter and was eventually deposited in the Hunterian Museum in London. In 1909, Harvey Cushing, a neurosurgeon from Boston, together with Sir Arthur Keith, the curator of the Hunterian Museum, examined the skeleton and opened the skull. They reported that the patient had an enlarged pituitary fossa ${ }^{1}$ (Fig. 1E) and concluded that this case of gigantism was most likely due to a pituitary adenoma. ${ }^{19}$ Radiographic images of the wrist bones, obtained in 1980, showed that the epiphyses were not fused at the time of the patient's death, at which point his bone age was estimated to be only about 17 years, according to current criteria. $^{2}$

The family trees of the affected members of the four families of Northern Irish origin are shown in Figure 2; their case histories are provided in the Supplementary Appendix, available with the full text of this article at NEJM.org.

Patients and family members gave written informed consent for the study, which was approved by the relevant local ethics committees. The board of directors of the Hunterian Museum gave us permission to examine teeth from the 18th-century index patient.

\section{METHODS}

Data on serum growth hormone levels for the four families were converted to current units (micrograms per liter) with the use of appropriate conversion factors related to the growth- 


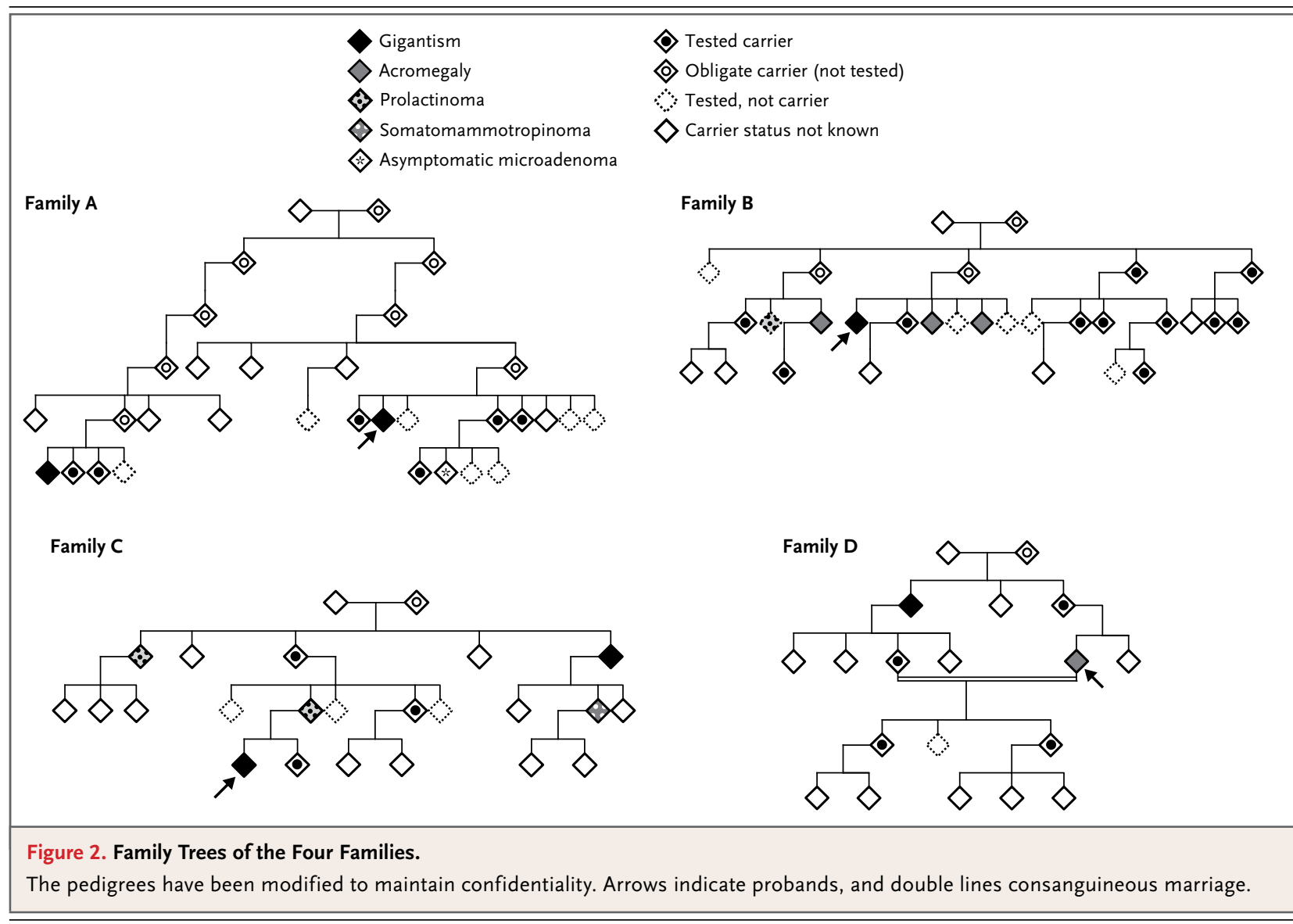

hormone standards applied at the time (World Health Organization International Reference Preparations [IRP] 66/217 and 80/505). DNA from peripheral-blood leukocytes was extracted with the use of a commercial kit (Nucleon BACC Genomic DNA Extraction Kit, GE Healthcare). DNA was extracted from the dental samples from the index patient in a separate laboratory (Mainz, Germany) with the use of previously described methods. ${ }^{20}$ The sequencing primers were as follows: for leukocyte DNA, forward primer GTGGCATCCTCAGGTCAG and reverse primer GTGGAGCAGCTCAGCAGAC; for the dental samples, forward primer CCCAGGAGGCCCAGGCTGACTTTG and reverse primer TCTGCCGGATCCGTGCCTCCAG. Microsatellites and corresponding primers were identified on the National Center for Biotechnology Information Web site (www.ncbi.nlm.nih.gov) and the University of California Santa Cruz Genome Browser Web site (http://genome.ucsc.edu). Simple repeats were identified with the use of the latter Web site and were designed accordingly for the specific region.
Sequencing and fragment analysis were carried out according to standard protocols on a DNA analyzer (ABI 3730, Applied Biosystems). Sequences were compared with the published template (accession number, NM_003977) with the use of the Mutation Surveyor, version 3.20 (SoftGenetics), and microsatellite data were analyzed with the use of GeneMarker, version 1.85 (SoftGenetics). The March 2006 assembly (NCBI36/hg18) of the human genome was used for localization of the markers (Fig. 1 in the Supplementary Appendix). Data from all available family members, including several subjects from the consanguineous family (Family D), were used to establish phase and disease-associated haplotype.

To estimate the time since the common ancestor of the mutant AIP allele in the four families and in the index patient, we applied coalescent theory, which is a retrospective model of gene genealogies for a sample from a population with a defined demographic history. ${ }^{21,22}$ Coalescent simulations were performed assuming a neutral locus in a random-mating population of 200,000 
chromosomes. (Other assumed population sizes that ranged from 2000 to 2 million chromosomes were tested, and the results were similar.) We used two different data sets to calculate the genetic distances for our area of interest. The Rutgers Combined Linkage-Physical Map ${ }^{23}$ combines genotype data from the Centre d'Etude du Polymorphisme Humain (Paris) and from deCODE (Reykjavik, Iceland) pedigrees, as well as sequencebased positional information; we used the sexaveraged genetic distance across our region. We also used population-based methods of estimating recombination rates from phase 2 HapMap data (all populations combined, http://hapmap .ncbi.nlm.nih.gov/downloads/recombination/latest/ rates). Taking each estimate in turn, and assuming a microsatellite mutation rate of 0.001 per generation, we calculated that the total rate of recombination plus mutation at all five microsatellite loci and the 304 codon of AIP was 0.0224 (Rutgers) or 0.0165 (HapMap) per generation. ${ }^{24}$ We used the method described by Donnelly and colleagues ${ }^{25}$ to estimate the time to the most recent ancestral gene copy, given the genotyping data. To estimate the number of carriers of the c.910 $\rightarrow$ T mutation living in a single generation today, we performed forward simulations, ${ }^{26}$ assuming a population growth of $2 \%$ per generation from an ancestral population of 10,000 (results were little affected by changes in these values). The assumed times to the most recent ancestral gene copy were drawn from the distribution obtained above, and simulations were performed with the condition that the present generation includes at least four carriers. Microtomographic images of the skull of the index patient were obtained at the Natural History Museum in London with the use of the HMX ST 225 cone-beam system (X-Tek) and were virtually dissected with the use of VGStudio MAX 2.0 (Volume Graphics).

\section{RESULTS}

Two teeth were removed from the skull of the index patient. After the extraction of DNA, polymerase-chain-reaction amplification and sequencing were performed on both tooth samples for the region flanking the R304 site in four different reactions. All eight products contained the heterozygous c. $910 \mathrm{C} \rightarrow \mathrm{T}$ change.

To investigate whether the four families carry the c.910C $\rightarrow \mathrm{T}$ mutation by common descent, we typed seven microsatellites distal to and seven proximal to AIP in subjects from the four living families and from the index patient (Fig. 3, and Fig. 1 in the Supplementary Appendix). We found a single common haplotype in a region between microsatellite markers Chr11-64-TG-110 and D11S987 spanning 2.68 megabases $(\mathrm{Mb})$ shared among all five lineages. The shared haplotype might extend from Chr11-64-AC-110 to Chr1167-TG-107, covering $3.50 \mathrm{Mb}$, but to be conservative, we used the minimal shared region $(2.68 \mathrm{Mb})$ in our calculations. We also typed these microsatellites in a sporadic case of gigantism in a patient from India who carried the c.910C $\rightarrow$ T mutation. This patient did not share the common haplotype found in the four Irish families. Since the validated microsatellites are highly polymorphic in the common region (heterozygosity scores between 0.58 and 0.82, National Center for Biotechnology Information [http://ncbi.nlm.nih.gov]), the sharing of the five microsatellite alleles and the c. $910 \mathrm{C} \rightarrow \mathrm{T}$ mutation in AIP strongly supports the hypothesis of a single, shared haplotype spanning this genomic region and carrying the same founder c. $910 \mathrm{C} \rightarrow \mathrm{T}$ mutation.

According to the Rutgers genetic map, the genetic distance across the minimal region $(2.68 \mathrm{Mb}$, including the five markers shared by the index patient and the four families) is 1.74 centimorgans (cM), whereas the population-based HapMap data results in a map distance of $1.15 \mathrm{cM}$. Both estimates are subject to some uncertainty, and the true map distance probably lies between these estimates. Given the observation of a shared haplotype, the coalescent-theory estimate of the time since the most recent common ancestor is 57 generations (95\% credible interval, 15 to 132), or between 375 and 3300 years ago, assuming a mean intergenerational time of 25 years, ${ }^{27}$ based on the Rutgers genetic-map distance, and 66 generations (95\% credible interval, 17 to 150 ), or between 425 and 3750 years ago, based on the HapMap estimate. With the condition that the present generation includes at least four carriers, and with the use of the above distribution of values for the number of generations since the mutation arose, forward simulations indicate that the expected number of carriers in one generation would be 68 (95\% credible interval, 5 to 350) and 90 (95\% credible interval, 5 to 500 ), according to the two genetic-map estimates, respectively. 


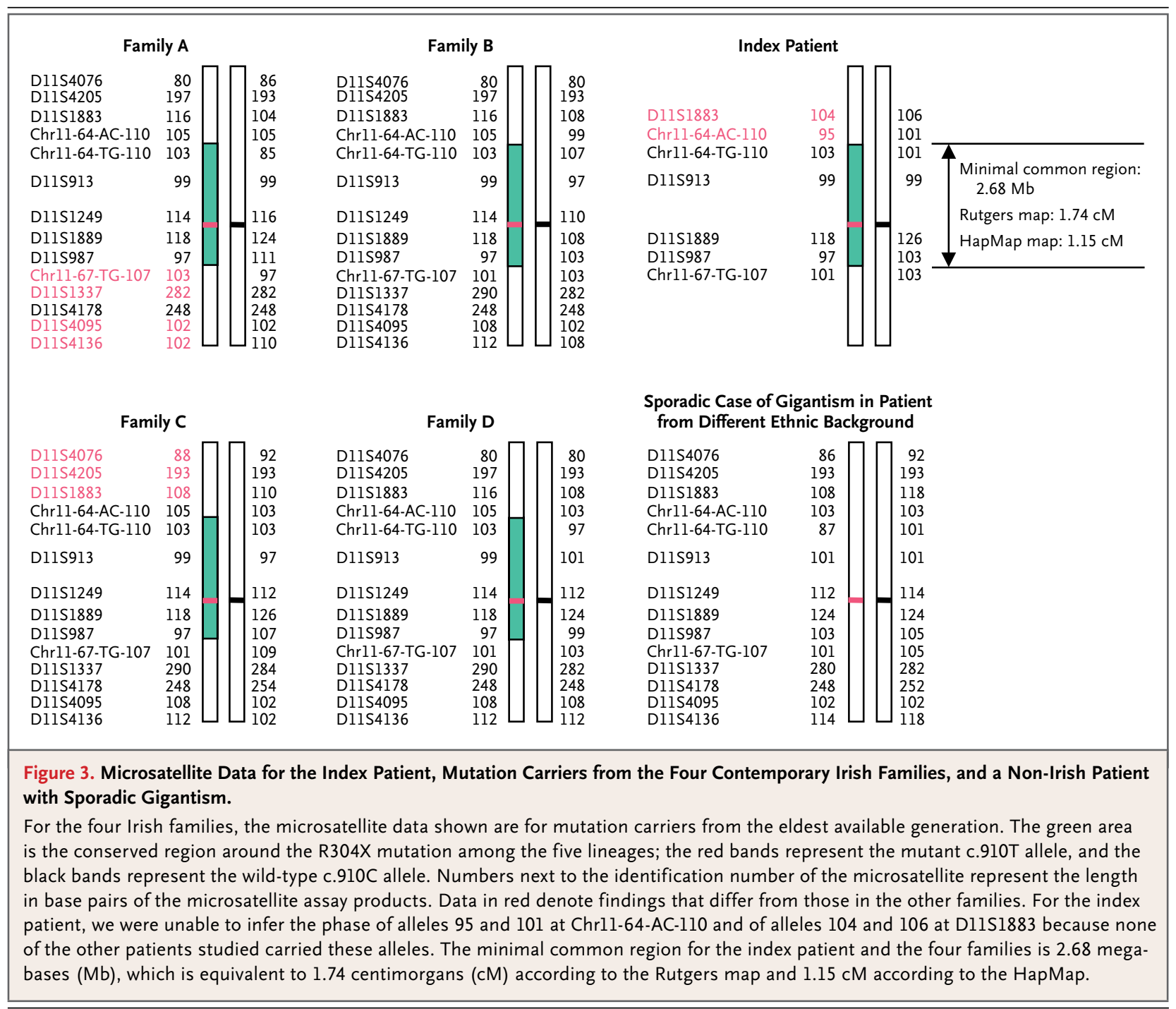

\section{DISCUSSION}

We identified a common haplotype that includes the c.910C $\rightarrow$ T, p.R304X AIP mutation in four families with familial isolated pituitary adenoma and in a giant from 18th-century Northern Ireland; this haplotype was absent in a sporadic case of gigantism in a patient from outside the British Isles who also carries this hotspot mutation. We suggest that these Irish patients with gigantism, acromegaly, and prolactinoma, including the index patient, carry the c.910C $\rightarrow$ T mutation through a common ancestry. Furthermore, coalescent analysis allowed us to estimate that the mutant allele was carried by an ancestor around 57 to 66 gen- erations ago (1425 to 1650 years ago), although the $95 \%$ credible intervals for this estimate are wide. The number of carriers of this haplotype in the generations of family members who are now alive could be several hundred.

We describe 14 mutation-positive subjects: 10 with growth hormone-secreting adenomas, 2 with prolactin-secreting adenomas, 1 with mixed growth hormone- and prolactin-secreting adenoma, and 1 with a microadenoma but no apparent hormonal abnormalities. Eight of these 10 subjects had childhood-onset disease (7 had gigantism and 1 had a macroprolactinoma), 4 had a history compatible with pituitary apoplexy, and 3 were identified as a result of clinical screening 
of carrier subjects. Pituitary adenomas do not become manifest in every person who carries the heterozygous AIP mutation, a finding that is consistent with previous observations. ${ }^{6-10,13}$ In the four families, we identified 51 carriers of the mutation but only 14 affected subjects. The level of penetrance, however, is difficult to establish, since we lack genetic and clinical data for all the carriers and for the subjects who are at risk for inheriting the mutation. Furthermore, there is an ascertainment bias for the presentation of affected subjects; thus, the true penetrance is probably lower than can be predicted from the available data.

On the basis of these studies, we believe that the index patient, and possibly the giant twin brothers from the neighboring village who lived contemporaneously (if indeed they were related to the index patient [Fig. 1D]), carried the same founder mutation as the four contemporary families of Northern Irish origin whom we have evaluated.

Gigantism and acromegaly have been described since ancient times. ${ }^{28}$ Wier provided the first accurate medical description of acromegaly in the 16th century, ${ }^{29}$ whereas the name of the disease and the identification of the full clinical picture originate from Pierre Marie. ${ }^{30}$ The link between a pituitary adenoma and clinical acromegaly and gigantism was not recognized until the second part of the 19th century. ${ }^{31-33}$ Acromegaly was initially considered to be an acquired disease, whereas gigantism was considered to be a congenital disorder. ${ }^{34}$ With data emerging on AIP mutations in patients with familial acromegaly, it appears that this old dogma might, ultimately, have some truth, since we have now shown that one of the most famous giants in the medical literature did indeed harbor an inherited predisposition to the disease and that the mutation responsible for this predisposition persists in the contemporary population of Ireland.

Supported by a Medical Research Council Training Fellowship (to Dr. Chahal) and by grants from the National Institute for Health Research (United Kingdom) and from Barts and the London Charity.

Disclosure forms provided by the authors are available with the full text of this article at NEJM.org.

We thank the patients and their family members for their participation in the study; Mr. Martyn Cooke, Head of Conservation at the Museums of the Royal College of Surgeons of England for the collection of dental samples; Professor David Barford (London) for the model of the AIP protein; and Dr. Stephanie Baldeweg (London), Mr. Ronan McClosky (Belfast), Professor John Wass (Oxford), and Dr. Wouter de Herder (Rotterdam) for their help in uncovering this story.
REFERENCES

1. Keith A. An inquiry into the nature of skeletal changes in acromegaly. Lancet 1911;1:993-1002.

2. Landolt AM, Zachmann M. The Irish giant: new observations concerning the nature of his ailment. Lancet $1980 ; 1$ 1311-2.

3. Bergland RM. New information concerning the Irish giant. J Neurosurg 1965; 23:265-9.

4. Melmed S. Acromegaly pathogenesis and treatment. J Clin Invest 2009;119:3189202.

5. Idem. Acromegaly. N Engl J Med 2006; 355:2558-73. [Erratum, N Engl J Med 2007; 356:879.]

6. Vierimaa O, Georgitsi M, Lehtonen $\mathrm{R}$, et al. Pituitary adenoma predisposition caused by germline mutations in the AIP gene. Science 2006;312:1228-30.

7. Daly AF, Vanbellinghen JF, Khoo SK, et al. Aryl hydrocarbon receptor-interacting protein gene mutations in familial isolated pituitary adenomas: analysis in 73 families. J Clin Endocrinol Metab 2007;92:1891-6.

8. Naves LA, Daly AF, Vanbellinghen JF, et al. Variable pathological and clinical features of a large Brazilian family har- boring a mutation in the aryl hydrocarbon receptor-interacting protein gene. Eur J Endocrinol 2007;157:383-91.

9. Jennings JE, Georgitsi M, Holdaway I, et al. Aggressive pituitary adenomas occurring in young patients in a large Polynesian kindred with a germline R271W mutation in the AIP gene. Eur J Endocrinol 2009;161:799-804.

10. Leontiou CA, Gueorguiev M, van der Spuy J, et al. The role of the aryl hydrocarbon receptor-interacting protein gene in familial and sporadic pituitary adenomas. J Clin Endocrinol Metab 2008;93:2390-401. 11. Georgitsi M, De Menis E, Cannavò S, et al. Aryl hydrocarbon receptor interacting protein (AIP) gene mutation analysis in children and adolescents with sporadic pituitary adenomas. Clin Endocrinol (Oxf) 2008;69:621-7.

12. Cazabat L, Libè $\mathrm{R}$, Perlemoine $\mathrm{K}$, et al. Germline inactivating mutations of the aryl hydrocarbon receptor-interacting protein gene in a large cohort of sporadic acromegaly: mutations are found in a subset of young patients with macroadenomas. Eur J Endocrinol 2007;157:1-8.

13. Igreja $\mathrm{S}$, Chahal $\mathrm{HS}$, King $\mathrm{P}$, et al. Characterization of aryl hydrocarbon re- ceptor interacting protein (AIP) mutations in familial isolated pituitary adenoma families. Hum Mutat 2010;31:950-60.

14. Stratakis CA, Tichomirowa MA, Boikos S, et al. The role of germline AIP, MEN1, PRKAR1A, CDKN1B and CDKN2C mutations in causing pituitary adenomas in a large cohort of children, adolescents, and patients with genetic syndromes. Clin Genet 2010;78:457-63.

15. Chahal HS, Chapple JP, Frohman LA, Grossman AB, Korbonits M. Clinical, genetic and molecular characterization of patients with familial isolated pituitary adenomas (FIPA). Trends Endocrinol Metab 2010;21:419-27.

16. Krawczak M, Ball EV, Cooper DN. Neighboring-nucleotide effects on the rates of germ-line single-base-pair substitution in human genes. Am J Hum Genet 1998;63:474-88.

17. Petrulis JR, Perdew GH. The role of chaperone proteins in the aryl hydrocarbon receptor core complex. Chem Biol Interact 2002;141:25-40.

18. Occhi G, Jaffrain-Rea ML, Trivellin G, et al. The R304X mutation of the Aryl hydrocarbon receptor Interacting Protein gene in familial isolated pituitary adeno- 
mas: mutational hot-spot or founder effect? J Endocrinol Invest 2010 March 30 (Epub ahead of print).

19. Cushing $\mathrm{H}$. The pituitary body and its disorders: clinical states produced by disorders of the hypophysis cerebri. Philadelphia: J.B. Lippincott, 1912.

20. Bramanti B, Thomas MG, Haak W, et al. Genetic discontinuity between local hunter-gatherers and central Europe's first farmers. Science 2009;326:137-40.

21. Nordborg M. Coalescent theory. In: Balding DJ, Bishop M, Cannings C, eds. Handbook of statistical genetics. 3rd ed. Chichester, England: John Wiley, 2007: 843-77.

22. Kingman JFC. The coalescent. Stochastic Processes Appl 1982;13:235-48.

23. Matise TC, Chen F, Chen W, et al.

A second-generation combined linkage physical map of the human genome. Genome Res 2007;17:1783-6.

24. Ellegren H. Microsatellites: simple sequences with complex evolution. Nat Rev Genet 2004;5:435-45

25. Donnelly P, Tavaré S, Balding DJ, Griffiths RC. Estimating the age of the common ancestor of men from the ZFY intron. Science 1996;272:1357-9.

26. Livi Bacci M. A concise history of world population. 3rd ed. Malden, MA Blackwell, 2001.

27. Thomas MG, Stumpf MP, Härke $H$ Evidence for an apartheid-like social structure in early Anglo-Saxon England. Proc Biol Sci 2006;273:2651-7.

28. Myers CS. The bones of Hen Nekht, an Egyptian king of the Third Dynasty. Man (Lond) 1901;127:152-3.

29. Wier J. Medicarum Observationum.
In: Virgo Gygantea ex quartana reddita. Basel, Switzerland: Oporinus, 1567:7-10.

30. Marie P. Sur deux cas d'acromégalie; hypertrophic singulière non congénitale des extrémités supérieures, inférieures et céphalique. Rev Med Liege 1886;6:297333.

31. Verga A. Caso singolare de prosopectasia. Sci Lett Bendiconti Clin Sci Mat Nat 1864;1:111-7.

32. Minkowski O. Über einem Fall von Akromegalie. Berl Klin Wochenschr 1887; 21:371-4.

33. Massalongo R. Sull'acromegalia. Riforma Med 1892;8:74.

34. Langer K. Über Wachstum des menschlichen Skelets, mit Bezug auf den Riesen. Denkschr Kais Akad Wissenschzu Wien Math Nat 1872:31.

Copyright @ 2011 Massachusetts Medical Society. article published in January 1812. The entire archive is fully searchable, and browsing of titles and tables of contents is easy and available to all. Individual subscribers are entitled to free 24-hour access to 50 archive articles per year. Access to content in the archive is available on a per-article basis and is also being provided through many institutional subscriptions. 